\title{
Metabolic Syndrome and Suicidal Ideation in Korean Based on the 2010 Korean National Health and Nutrition Examination Survey
}

\author{
Sun-Mi Kim¹, Cheol-Soon Lee ${ }^{1 凶}$, Chul-Soo Park ${ }^{1}$, Bong-Jo Kim¹, \\ Boseok Cha', So-Jin Lee', Ji-Yeong Seo', and Jaemin Kim² \\ ${ }^{1}$ Department of Psychiatry, School of Medicine, Gyeongsang National University, Jinju, Republic of Korea \\ ${ }^{2}$ Institute for Work and Health, Toronto, Canada
}

The aim of this study was to investigate the relationship between metabolic syndrome and suicidal ideation in Korean. This study was based on the 2010 Korean National Health and Nutrition Examination Survey. A questionnaire was used to measure suicidal ideation and physical examination was performed to measure waist circumference, blood pressure, fasting glucose, cholesterol and triglyceride levels. Complex samples logistic regression was performed to estimate the relationship between metabolic syndrome and suicidal ideation among adults and adolescents. Subjects with metabolic syndrome were more likely to have suicidal ideation in adult. There would be essential needs to evaluate suicidal ideation in adult with metabolic syndrome and to follow up suicidal ideation in adolescents with metabolic syndrome.

Psychiatry Investig 2014;11(3):325-329

Key Words Suicidal ideation, Metabolic syndrome.

\section{INTRODUCTION}

In South Korea, the suicide rate is 28.1 per 100,000, which is much higher than the OECD average of 11.3 per $100,000{ }^{1,2}$ According to the 2010 report of Korea Statistics, suicide-related mortality reached 31.2 per 100,000 , which was a twofold increase from 2000 and suicide was the leading cause of death among people in their 10s and 30s in South Korea. ${ }^{2}$ These statistics indicate that suicide is a growing problem in Korea, especially among the young. Youth suicide results in the loss of productive activity in a social context. ${ }^{3}$ Suicide is a tragedy to the person's family and friends as well as to the larger society to which the victim belonged. ${ }^{4}$ The lifetime of prevalence of suicidal ideation in South Korea was 15.2\% and unplanned suicide attempters experience suicidal ideation., ${ }^{5,6}$

Metabolic syndrome (MS) refers to the simultaneous presence of impaired glucose tolerance, obesity, dyslipidemia and

Received: May 30, 2013 Revised: October 22, 2013

Accepted: December 2, 2013 Available online: July 21, 2014

$\triangle$ Correspondence: Cheol-Soon Lee, MD, PhD

Department of Psychiatry, School of Medicine, Gyeongsang National University, 79 Gangnam-ro, Jinju 660-702, Republic of Korea

Tel: +82-55-750-8872, Fax: +82-55-759-0003, E-mail: psy@gnu.ac.kr

(a) This is an Open Access article distributed under the terms of the Creative Commons Attribution Non-Commercial License (http://creativecommons.org/licenses/by$\mathrm{nc} / 3.0$ ) which permits unrestricted non-commercial use, distribution, and reproduction in any medium, provided the original work is properly cited. hypertension and is a serious health problem globally. ${ }^{7}$ The incidence of MS is also growing quite rapidly in concert with improvements in the standard of living and lifestyle. In the Korean population, the prevalence is approximately $9-25 \%{ }^{8,9}$ The prevalence of MS among children and adolescents is approximately $10 \%$ and is highly correlated with obesity. ${ }^{10} \mathrm{MS}$ is considered a risk factor for cardiovascular disease and diabetes. ${ }^{11} \mathrm{MS}$ is also related with depression ${ }^{12}$ and decreased cognitive function in elderly people. ${ }^{13}$ Thus, MS is related to not only cardiovascular diseases but also poor mental health. But, there are just few study associated relationship between MS and suicidal ideation. This study aimed to determine how MS may be related to suicidal ideation in a Korean based on the Korean representative survey.

\section{METHODS}

This study was conducted using data collected by the 2010 Korean National Health and Nutrition Examination Survey ${ }^{14}$ via a questionnaire and physical examination. The questionnaire was conducted by trained interviewer according to the survey policy using an interview format and asked questions about education and economic activities; for the remaining items on smoking, drinking and physical exercise, respondents completed the survey on their own time. The informed con- 
sent was complete in the interview. The physical examinations included measurements, observations and specimen analyses. This survey was conducted upon the approval of the research ethical review board of the Korean Centers for Disease Control and Prevention.

MS was defined based on the 2001 National Cholesterol Education Program-Third Adult Treatment Panel (NECP-ATP III) guidelines along with the waist circumference values for Koreans suggested by the Korean Society for the Study of Obesity. ${ }^{15,16}$ MS was diagnosed if three or more of the following criteria were met: 1 ) waist circumference, male $\geq 90 \mathrm{~cm}$, female $\geq 85 \mathrm{~cm}$; 2) either SBP $\geq 130 \mathrm{~mm} \mathrm{Hg}$ or DBP $\geq 85 \mathrm{~mm} \mathrm{Hg}$ or specific medication; 3) FPG $\geq 100 \mathrm{mg} / \mathrm{dL}$ or specific medication for diabetes or previous diagnosis of Type 2 diabetes; 4) HDL-C, male $<40 \mathrm{mg} / \mathrm{dL}$, female $<50 \mathrm{mg} / \mathrm{dL}$; and 5) TAG $\geq 150 \mathrm{mg} / \mathrm{dL}$ or specific medication. When it comes to MS in adolescents, cut-off values, which were modified for adolescents based on the 2001 NECP-ATP III criteria, were used. ${ }^{15}$ Waist circumference, blood pressure and gender percentiles of the 2007 standard measures for Korean children and adolescent were also used as a reference. ${ }^{17} \mathrm{MS}$ was diagnosed if three or more of the following criteria were met: 1) waist circumference $\geq$ sex, and age-specific 90th percentile; 2) either SBP or DBP $\geq$ sex, age and height-specific 90th percentile, use of blood pressure-lowering medication or a previous diagnosis of hypertension; 3) FPG $\geq 100 \mathrm{mg} / \mathrm{dL}$, current diabetes status or current use of insulin or hypoglycemic medication; 4) HDL-C $\leq 40 \mathrm{mg} / \mathrm{dL}$; and 5) TAG $\geq 110 \mathrm{mg} / \mathrm{dL}$.

When it comes to suicidal ideation, respondents were asked if they had thought of suicide over the last year, to which they responded 'Yes' or 'No'. Age, sex, education level and monthly household income were included. To assess the depressed mood, respondents were asked if they felt persistently sad or hopeless to such an extent that their everyday life was affected for two weeks or longer over the last year to the extent their daily life was affected. Respondents were asked whether they experience stress in their daily lives. Response choices ranged from "never or a little" to "often or very often." Smoking, drinking status, sleep duration and physical exercise were investigated. Height and weight were measured to compute their BMI. Their waist circumference was then measured. Blood pressure was measured after respondents had a $5 \mathrm{~min}$ utes period of rest. The blood sample was taken after at least 8 hours of fasting to assess fasting glucose, total and HDL cholesterols and triglyceride levels.

\section{Statistical analysis}

In the Korean National Health and Nutrition Examination Survey, samples were randomly selected using a systematic sampling method. Adjusted weights for sex, age, and region were applied to data to obtain a representative sample of the Korean population. A complex sample analysis was performed based on an analysis plan file in which weights, stratification variables and primary sampling units were designated. Miss-

Table 1. Characteristics of the participants in the Korean National Health and Nutrition Examination Survey 2010 (N=7,535)

\begin{tabular}{lc}
\hline \multicolumn{1}{c}{ Characteristics } & N (weighted \%) or \\
& Mean (standard error) \\
\hline Age, years & $41.8(0.4)$ \\
Sex & \\
Male & $3,142(50.0)$ \\
Female & $3,942(50.0)$ \\
Education level & \\
Below and elementary school & $2,023(23.0)$ \\
Middle school & $938(13.6)$ \\
High school & $2,112(34.3)$ \\
College and above & $1,905(29.0)$ \\
Monthly income (1 million wons) & $418.7(23.6)$ \\
Smoking state & \\
Yes & $1,388(24.9)$ \\
No & $5,616(75.1)$ \\
Alcohol drinking & \\
Yes & \\
No & $32.9(0.2)$ \\
Regular physical exercise & $3,404(53.7)$ \\
Yes & $3,600(46.3)$ \\
Notal cholesterol (mg/dL) &
\end{tabular}

The sum of the total in a subgroup does not equal the total number of participants in this study because information was not available for a few participants. BMI: body mass index, SBP: systolic blood pressure, DBP: diastolic blood pressure, HDL: high density lipoprotein 
ing data were included in the complex sample analysis to produce results based on the instructions for the data analysis of the national survey data used in this study. ${ }^{14}$ The general linear model and Chi-square tests were performed to determine differences in variables after each adults and adolescents were divided into two groups based on the presence or absence of suicidal ideation. Complex sample logistic regression was used to determine the relationship between metabolic syndrome and suicidal ideation. The collected data were analyzed using PASW Statistics version 18.0 (SPSS Inc., Chicago, IL, USA). A p-value of less than 0.05 was considered statistically significant.

Table 2. Comparison of characteristics between suicidal ideation cases and non-cases between Korean Adolescents and adults in the Korean National Health and Nutrition Examination Survey 2010 (N=7004)

\begin{tabular}{|c|c|c|c|c|c|c|}
\hline \multirow[b]{2}{*}{ Characteristics } & \multicolumn{3}{|c|}{ Adolescents } & \multicolumn{3}{|c|}{ Adults } \\
\hline & $\begin{array}{l}\text { Suicidal ideation } \\
\qquad(\mathrm{N}=93)\end{array}$ & $\begin{array}{c}\text { Non-suicidal } \\
\text { ideation }(\mathrm{N}=636)\end{array}$ & $\mathrm{p}$ & $\begin{array}{l}\text { Suicidal ideation } \\
\qquad(\mathrm{n}=945)\end{array}$ & $\begin{array}{c}\text { Non-suicidal } \\
\text { ideation }(\mathrm{N}=5,307)\end{array}$ & $\mathrm{p}$ \\
\hline Age, years & $15.2(0.2)$ & $15.1(0.1)$ & 0.69 & $48.8(0.8)$ & $44.2(0.5)$ & $<0.01^{*}$ \\
\hline Sex & & & $<0.01^{*}$ & & & $<0.01^{*}$ \\
\hline Male & $31(29.9)$ & $365(58.7)$ & & $272(31.3)$ & $2,432(52.7)$ & \\
\hline Female & $62(70.1)$ & $271(41.3)$ & & $673(68.7)$ & $2,875(47.3)$ & \\
\hline Monthly income (1 million wons) & $471.5(82.6)$ & $430.3(41.5)$ & 0.63 & $359.7(33.5)$ & $429.4(25.7)$ & $0.02^{*}$ \\
\hline Smoking state & & & 0.12 & & & 0.17 \\
\hline Yes & $9(15.9)$ & $44(8.3)$ & & $191(24.4)$ & $1,144(27.3)$ & \\
\hline No & $84(84.1)$ & $592(91.4)$ & & $754(75.6)$ & $4,163(72.7)$ & \\
\hline Alcohol drinking & & & 0.93 & & & $<0.01^{*}$ \\
\hline Yes & $7(14.0)$ & $67(14.6)$ & & $438(50.3)$ & $2,892(60.2)$ & \\
\hline No & $86(86.0)$ & $569(85.4)$ & & $507(49.7)$ & $2,415(39.8)$ & \\
\hline Regular physical exercise & & & 0.20 & & & 0.97 \\
\hline Yes & $28(22.4)$ & $192(30.2)$ & & $207(22.3)$ & $1,114(22.3)$ & \\
\hline No & $65(77.6)$ & $444(69.8)$ & & $738(77.7)$ & $4,193(77.7)$ & \\
\hline Sleep duration (h) & $9.2(1.2)$ & $8.4(0.5)$ & 0.48 & $6.9(0.2)$ & $7.0(0.1)$ & 0.47 \\
\hline Subjective stress level & & & $<0.01^{*}$ & & & $<0.01^{*}$ \\
\hline High & $53(56.1)$ & $120(20.0)$ & & $536(58.2)$ & $1,172(23.0)$ & \\
\hline Low & $40(43.9)$ & $516(80.0)$ & & $409(41.8)$ & $4,135(77.0)$ & \\
\hline Depressed mood & & & $<0.01^{*}$ & & & $<0.01^{*}$ \\
\hline Yes & $27(30.3)$ & $38(7.6)$ & & $441(46.5)$ & $383(6.8)$ & \\
\hline No & $66(69.7)$ & $598(92.4)$ & & $504(53.5)$ & $4,924(93.2)$ & \\
\hline Height $(\mathrm{cm})$ & $163.4(1.0)$ & $165.1(0.5)$ & 0.13 & $160.5(0.4)$ & $164.6(0.2)$ & $<0.01^{*}$ \\
\hline Weight $(\mathrm{kg})$ & $56.2(1.6)$ & $57.4(0.7)$ & 0.51 & $61.4(0.5)$ & $64.1(0.2)$ & $<0.01^{*}$ \\
\hline Waist circumference $(\mathrm{cm})$ & $70.4(1.4)$ & $70.6(0.5)$ & 0.90 & $81.4(0.5)$ & $80.7(0.2)$ & 0.13 \\
\hline $\mathrm{BMI}\left(\mathrm{kg} / \mathrm{m}^{2}\right)$ & $21.0(0.6)$ & $21.0(0.2)$ & 0.98 & $23.8(0.2)$ & $23.6(0.1)$ & 0.23 \\
\hline \multicolumn{7}{|l|}{ Blood pressure levels (mm Hg) } \\
\hline SBP & $102.5(1.4)$ & $106.1(0.6)$ & $0.01^{*}$ & $118.3(0.6)$ & $116.5(0.4)$ & $<0.01^{*}$ \\
\hline $\mathrm{DBP}$ & $64.1(1.3)$ & $65.6(0.5)$ & 0.24 & $73.9(0.4)$ & $74.6(0.3)$ & 0.11 \\
\hline Fasting plasma glucose (mg/dL) & $87.5(0.8)$ & $88.5(0.3)$ & 0.26 & $98.4(1.5)$ & $96.1(0.4)$ & 0.11 \\
\hline Total cholesterol (mg/dL) & $163.2(3.4)$ & $153.8(0.3)$ & $0.01^{*}$ & $187.8(1.5)$ & $186.5(0.7)$ & 0.40 \\
\hline HDL-cholesterol (mg/dL) & $54.6(1.6)$ & $53.1(0.5)$ & 0.33 & $53.4(0.6)$ & $52.7(0.2)$ & 0.33 \\
\hline Triglycerides (mg/dL) & $85.5(4.7)$ & $82.3(2.9)$ & 0.57 & $133.2(4.7)$ & $133.9(2.3)$ & 0.89 \\
\hline Metabolic syndrome & & & 0.22 & & & $<0.01^{*}$ \\
\hline Presence & $5(6.5)$ & $18(3.1)$ & & $269(28.8)$ & $1274(22.4)$ & \\
\hline Absence & $73(93.5)$ & $542(96.9)$ & & $580(71.2)$ & $3747(77.6)$ & \\
\hline
\end{tabular}

Values are presented as unweighted $\mathrm{n}$ (weighted \%) or as the mean (standard error). The sum of the adolescents and adults in the subgroup does not equal the total number of participants in this study because information was not available for a few participants. $p$ values were obtained by general linear model or chi-square test, ${ }^{*} \mathrm{p}<0.05$. BMI: body mass index, SBP: systolic blood pressure, DBP: diastolic blood pressure, HDL: high density lipoprotein 


\section{RESULTS}

This study involved a total of 7,535 respondents, including 795 adolescents aged 12 to 18 and 6,740 adults aged over 19 . Basic demographic data were shown in Table 1. A total of 7,004 respondents (response rate: 93\%) answered the survey item about the presence or absence of suicidal ideation. In the terms of comparison of suicidal ideation, Adult groups have significant difference in metabolic syndrome between suicidal groups and non-suicidal groups (Table 2). When it comes to complex sample logistic regression analysis, suicidal ideation was significantly associated with metabolic syndrome in whole sample $(\mathrm{OR}=1.43,95 \% \mathrm{CI}=1.19-1.72, \mathrm{p}<0.001)$ and adults sample $(\mathrm{OR}=1.40, \mathrm{CI}=1.16-1.69, \mathrm{p}<0.001)$. But, there are no significant in adolescent sample.

\section{DISCUSSION}

This study found a more significant association between metabolic syndrome and suicidal ideation in adolescents compared to adults. A study involving Korean women aged 15 to 85 also confirmed a positive correlation between metabolic syndrome and depression. ${ }^{18}$ Depression is possible mediating factor in the relationship between MS and suicidal ideation in Patients with metabolic syndrome. Low serotonin level which is common in depression and suicidal ideation also close related with each other. A study involving adults aged 24 to 60 reported the association of reduced central serotonergic response with high blood pressure, obesity, high blood sugar, triglycerides, insulin and insulin resistance. ${ }^{19}$ Given that a reduced concentration of 5-HIAA in the cerebrospinal fluid is known to be a biological factor predicting suicide, there may be a relationship between serotonin metabolism and suicide. Though all of suicidal ideation don't become suicide and suicide attempt, there are high possibility of suicidal ideation in person who have pending suicide.

A review on the psychological characteristics related to risk factors for metabolic syndrome described the risk of metabolic syndrome as mediated by hostility and anger. ${ }^{20}$ A study involving 5,662 respondents reported personality traits, such as impulsivity and hostility, as being related to metabolic syndrome. ${ }^{21}$ Another study described hostility in children and teenagers as a risk factor for metabolic syndrome. ${ }^{22}$ Adolescents have greater impulsivity to commit suicide due to their emotional and cognitive immaturity. ${ }^{23}$ When they were bullied as a result of their obesity, they tended to think about suicide, and the number of suicide attempts increased among that group. ${ }^{24}$ The finding in which teenagers with metabolic syndrome developed suicidal ideation is inconsistent with the results of this study. We can guess there are need to take time in order to induce suicidal ideation by metabolic syndrome. Otherwise, there might be possibility of change to have suicidal ideation when they become adult with metabolic syndrome through this study. So there is need more longitudinal study for perspective view to find this change.

This study contains limitations. First, the results of metabolic syndrome-related studies are very dependent on definitions of the criteria used in the study. ${ }^{25}$ This study used the NECP-ATP III guidelines for the diagnosis of metabolic syndrome and the Korean Society for the Study of Obesity's waist circumference values. The use of lower waist circumference cut-off values than those noted in the NCEP-ATP III standards might have led to a higher prevalence rate of metabolic syndrome. Second, only a single item was used as a measure of depressed mood and suicidal ideation, posing a limitation to the interpretation of the study results. Third, we didn't consider other confounders that can be related with suicidal ideation such as physical illness and school bullies. Additionally, the self-administered questionnaire responses may not have been honest or discrete for every case. Nonetheless, the results of this study can be generalized to a larger population because this study was based on data from a national study. Further studies that can provide information concerning other variables with prospective view would be useful for developing suicide prevention and intervention programs in patients with metabolic syndrome.

\section{REFERENCES}

1. OECD. Health at a Glance 2011: OECD Indicators. Paris: OECD Publishing; 2011.

2. Statistics Korea. Cause of Death Statistics in 2010. Seoul: Statistics Korea; 2011.

3. Roh MS, Jeon HJ, Lee HW, Lee HJ, Han SK, Hahm BJ. Suicide-related behaviors among the college students. J Korean Neuropsychiatr Assoc 2007;46:35-40.

4. Conwell Y, Van Orden K, Caine ED. Suicide in older adults. Psychiatr Clin North Am 2011;34:451-468.

5. Jeon HJ, Lee JY, Lee YM, Hong JP, Won SH, Cho SJ, et al. Life time prevalence and correlates of suicidal ideation, plan, and singel and multiple attempts in a Korean nationwide study. J Nerv Ment Dis 2010;198:643646.

6. Jeon HJ, Lee JY, Lee YM, Hong JP, Won SH, Cho SJ, et al. Unplanned versus planned suicide attempters, precipitants, methods, and an association with mental disorders in a Korea-based community sample. J Affect Disord 2010;127:274-280.

7. Park YW, Zhu S, Palaniappan L, Heshka S, Carnethon MR, Heymsfield SB. The metabolic syndrome: prevalence and associated risk factor findings in the US population from the Third National Health and Nutrition Examination Survey, 1988-1994. Arch Intern Med 2003;163: 427-436.

8. Lym YL, Hwang SW, Shim HJ, Oh EH, Chang YS, Cho BL. Prevalence and risk factors of the metabolic syndrome as defined by NCEP-ATP III. J Korean Acad Fam Med 2003;24:135-143.

9. Lim S, Shin H, Song JH, Kwak SH, Kang SM, Yoon JW, et al. Increasing prevalence of metabolic syndrome in Korea The Korean National Health and Nutrition Examination Survey for 1998-2007. Diabetes Care 
2011;34:1323-1328

10. Park MJ. Epidemiology of the metabolic syndrome among Korean children and adolescents. Korean J Pediatr 2008;51:564-568.

11. Löwe B, Hochlehnert A, Nikendei C. Metabolic syndrome and depression. Ther Umsch 2006;63:521-527.

12. Koponen H, Jokelainen J, Keinänen-Kiukaanniemi S, Kumpusalo E, Vanhala M. Metabolic syndrome predisposes to depressive symptoms: a population-based 7-year follow-up study. J Clin Psychiatry 2008;69: 178-182.

13. Yaffe K, Kanaya A, Lindquist K, Simonsick EM, Harris T, Shorr RI, et al. The metabolic syndrome, inflammation, and risk of cognitive decline. JAMA 2004;292:2237-2242.

14. Korea Centers for Disease Control and Prevention. Korea Health Statistics 2010: Korea National Health and Nutrition Examination Survey (KNHANES V-1). Cheongwon: Korea Centers for Disease Control and Prevention; 2011.

15. Expert Panel on Detection, Evaluation, and Treatment of High Bldd Cholesterol in Adults. Executive summary of the third report of the $\mathrm{Na}$ tional Cholesterol Education Program (NCEP) expert panel on detection, evaluation, and treatment of high blood cholesterol in adults (adult treatment panel III). JAMA 2001;285:2486-2497.

16. Lee SY, Park HS, Kim DJ, Han JH, Kim SM, Cho GJ, et al. Appropriate waist circumference cutoff points for central obesity in Korean adults. Diabetes Res Clin Pract 2007;75:72-80.

17. Korea Centerfor disease Control and Prevention, The Korean PediatricSociety, The Committee for the Development of Growth Standard for Korean Children and Adolescents. 2007 Korean Children and Adolescents Growth standard (commentart for the development of 2007 growth chart). Seoul: Division of Chronic Disease Surveillance in Korea Centers for Disease Control and Prevention; 2007.

18. Yoon DH, Park JH, Cho SC, Park MJ, Kim SS, Choi SH, et al. Depressive Symptomatology and Metabolic Syndrome in Korean Women. J Korean Soc Study Obes 2005;14:213-219.

19. Muldoon MF, Mackey RH, Williams KV, Korytkowski MT, Flory JD, Manuck SB. Low central nervous system serotonergic responsivity is associated with the metabolic syndrome and physical inactivity. J Clin Endocrinol Metab 2004;89:266-271.

20. Goldbacher EM, Matthews KA. Are psychological characteristics related to risk of the metabolic syndrome? A review of the literature. Ann Behav Med 2007;34:240-252.

21. Sutin AR, Costa PT Jr, Uda M, Ferrucci L, Schlessinger D, Terracciano A. Personality and metabolic syndrome. Age 2010;32:513-519.

22. Räikkönen K, Matthews KA, Salomon K. Hostility predicts metabolic syndrome risk factors in children and adolescents. Health Psychol 2003;22:279-286.

23. Shin MS, Park KB, Oh KJ, Kim ZS. A study of suicidal ideation among high school students: the structural relation among depression, hopelessness, and suicidal ideation. Korean J Clin Psychol 1990;9:1-19.

24. Daniels SR, Arnett DK, Eckel RH, Gidding SS, Hayman LL, Kumanyika $\mathrm{S}$, et al. Overweight in children and adolescents pathophysiology, consequences, prevention, and treatment. Circulation 2005;111:1999-2012.

25. Athyros VG, Ganotakis ES, Tziomalos K, Papageorgiou AA, Anagnostis $\mathrm{P}$, Griva T, et al. Comparison of four definitions of the metabolic syndrome in a Greek (Mediterranean) population. Curr Med Res Opin 2010;26:713-719. 